\title{
A sala de aula como espaço
}

\section{de comunicação:}

\author{
reflexões em torno do tema*
}

Pedro Geraldo Novelli ${ }^{1}$

NOVELI, P. The classroom as a space for communication: reflections on the theme. Interface - Comunicação, Saúde, Educação, v.1, n.1, 1997.

The classroom is the subject of these reflections. It is both a space and a social moment that deserves some consideration. It is a space that allows the building up of a specific relationship between teacher and pupil. We intend to look at this relationship through the lenses of dialectic and obtain contributions for the educational practice.

KEY WORDS: Teaching; interpersonal relations; communication; students.

Este artigo procura considerar a sala de aula enquanto espaço físico e social. Essa espacialidade possui algumas especificidades que a caracterizam como momento político e social. Contudo, a característica principal da sala de aula está na relação que ela estabelece entre os seus freqüentadores. Aqui tenta-se investigar a relação professor/aluno pela ótica da dialética e obter as possíveis contribuições para a prática pedagógica.

PALAVRAS-CHAVE: Ensino; relações interpessoais; comunicação; estudantes.

\footnotetext{
* Texto apresentado em mesa-redonda sobre Comunicação, organizada pelas disciplinas de Pedagogia Médica e Didática Especial dos Cursos de Pós-graduação da Faculdade de Medicina da UNESP, campus de Botucatu, em setembro de 1996.

${ }^{1}$ Professor do Departamento de Educação do Instituto de Biociências - IB /UNESP, campus de Botucatu.
} 
Uma sala é inicialmente um espaço que pode ou não ser ocupado. Quando se trata da sala de aula, o espaço deve necessariamente ser ocupado. Isso se deve ao fato de que a sala de aula é um espaço socialmente instituído. É um espaço historicamente conquistado e construído. Apesar de ser um espaço social, o acesso a ele não se encontra plenamente garantido. Outros espaços demandam dos indivíduos uma presença mais prolongada, senão definitiva. Além do mais, a ocupação de um dado espaço implica tempo disponível para tanto. No entanto, é possível haver espaço sem tempo para ocupá-lo; e estar num espaço sem tempo para aí estar é como não estar. De igual modo, pode haver tempo para estar sem, contudo, poder ocupar espaço algum. Novamente o tempo se inefetiva, pois não se situa. Dessa forma a sala de aula necessita da conjugação entre o espaço e o tempo que a constituem.

Um espaço é onde estar, acontecer, ser, viver. A sala de aula, posta como um espaço, situa-se como uma alternativa para estar. A alternativa funda-se na distinção para com outras possibilidades. A sala de aula partilha a categoria da espacialidade com outros espaços, mas a forma de sua ocupação cria a sua especificidade. Portanto, não basta a existência possível da sala de aula para que esta se torne sala de aula. Tal como um cenário, ela não basta para que um enredo todo se desenrole.

Da sala de aula resta analisar o que lhe é essencial, isto é, o que sem o qual deixa de ser o que é. É precisamente a atividade desenvolvida em seu interior que a distingue de outros espaços. Ao mesmo tempo, a sala de aula pode ser deslocada para lugares os mais diversos possíveis, pois sua atividade essencial extrapola limites físicos.

Historicamente a sala de aula foi e tem sido localizada no perímetro da escola. Dificilmente se consegue pensar em sala de aula separadamente da escola e vice-versa. A escola constitui-se o espaço social que procura garantir minimamente o tempo para sua ocupação. Cabe lembrar que a palavra escola deriva do grego e significa lugar do ócio. Os gregos antigos sabiam muito bem que a desocupação proporcionava tempo e espaço para o saber e sua procura. Além disso, a ociosidade, vista como ausência de um veículo ocupacional permanente, cria a possibilidade do cio, isto é, a reprodução da vida. Mesmo instintivamente, a vida é uma complexa elaboração de elementos e possibilidades. Tratase de um grande acontecimento. Talvez seja o acontecimento! Acontecer é realizar, romper a mesmice, viabilizar a diferença. A própria vida recupera-se enquanto distintiva em sua aniquilação pela morte. Assim ela desqualifica a imputação de banalidade sobre si. Conforme diz Hegel em sua obra "A Ciência da Lógica" (1968), o nada não deve ser compreendido unicamente como um vazio, pois sendo algo, ou seja, o próprio nada, já é algo e, desse modo, participa do ser, das coisas que são. Assim, o nada não é somente o 
que não é, mas mesmo não sendo também é. Essa insatisfação da vida responde pela sua insistência em existir.

Obviamente, pode-se discutir que não basta estar vivo, mas se faz necessário precisar como se vive. Isso parece aludir para o fato de que a vida pode ser sempre mais do que é $e$, ainda, que a vida resulta dos vivos. A vida faz e deixa-se fazer.

Ora, por que tanta conversa sobre a vida se a sala de aula às vezes é de matar? Ser de morte conduz ao acontecer e também implica ser de vida, pois a própria morte depende do que ela parece destruir. (Engels, 1883)

A sala de aula é de morte por abrigar vidas e, se distintas, ambas correm perigo. Entre os parecidos, acontece somente o imperceptível, posto que se tem tão somente a univocidade. Formalmente, a sala de aula é ocupada pelas figuras do professor e do aluno. O encontro ou desencontro entre essas figuras confirma a diferença como elo que os relaciona. Relacionar-se pela diferença significa afirmar o outro, a alteridade. Afirmar o outro é afirmar o próprio eu, pois o reconhecimento do eu passa pelo reconhecimento do que é distinto, diverso. A surpresa que o eu sente diante do outro é, concomitantemente, a surpresa de si mesmo. Isso é mais fácil de ser dito do que percebido porque o eu está sempre muito perto de si próprio. O afastamento necessário está no olhar dirigido ao outro. Mas, a admiração pelo outro, ou seja, este olhar para, também acarreta um certo receio porque o outro sempre é um desconhecido e, como tal, parece ameaçador. O eu tem razão em temer a ameaça advinda do outro porque qualquer contato com este redundará numa alteração no eu. Se isso não ocorresse a ameaça não seria sentida e ter-se-ia tão-somente a redução do outro ao eu. Por isso mesmo o eu se transtorna com o outro, pois ele destoa, não se torna prolongamento imediato do eu. Lidar com o desconhecido é extremamente desconfortável por isso o eu empreende esforços para entender o outro. Esse entendimento passa pelas categorias $e$ referências do próprio eu. Aliás, a crítica dirigida ao outro é dirigida de fora. Parece que assim não poderia deixar de ser, pois o encontro ocorre entre os que ocupam posições distintas. Entender o outro exige o olhar desde a posição desse outro e daí o que se tem, por reciprocidade, é a consciência da própria organização de entendimento.

No entanto, deve-se perguntar, por que reconhecer o outro? Daí, caberem algumas questões que talvez melhorem a primeira: a realidade é unívoca? Tudo é sempre o mesmo? O movimento é contingente? Como garantir-se sobre a veracidade do real sem referencial algum? Foucault diz em seu livro "Vigiar e Punir" (1980) que os olhos que são feitos para ver não vêem e somente vêem quando são vistos. O próprio pensar, a mínima consideração sobre a realidade, desdobra o eu num outro, numa distinção. Em outras palavras, a diferença encontra-se na gênese do próprio eu marcado, desde esse 
momento, pelo que o nega e contradiz. Isto viabiliza ao eu a identificação da contradição da alteridade, posto que, se a diferença fosse plena, nenhum reconhecimento teria lugar. Ao mesmo tempo, a identificação também não é absoluta, pois um desaparecia no outro. Portanto, o eu já é um outro e este já é um eu.

De tal concepção deriva uma compreensão de relação. A relação somente existe porque se tem dois posicionamentos. Estes, necessariamente, são distintos um do outro. O interesse por uma pessoa é despertado porque essa tal pessoa não faz parte do círculo familiar marcado pela mesmidade. "Não me peças que eu fique, pois foi andando que eu te encontrei." (autor desconhecido). O encontro, o desensimesmamento é provocado pela carência do eu que se descobre como eu e carente no outro. Até então o eu inexiste. "O ser em estado puro, indeterminado equivale ao nada." (Hegel, 1968; p.77) A mesma carência, a auto-insuficiência, proporciona a abertura ao outro que aí revela o eu para si mesmo. A completude do eu encontra-se no outro. Mas, o outro é sempre o outro e, se assim não for, a relação se desfaz. Por isso, o outro permanece um desconhecido, aquele que deve ser buscado sempre. Ser amante do outro é perceber-se ignorante do outro. Pitágoras empregou, pela primeira vez entre os gregos antigos, a auto-denominação de filósofo, o amigo, o amante da sabedoria. Os mesmos gregos sabiam que ninguém poderia ser filósofo definitivamente constituído. Afinal, o amante é o que está fazendo algo. É o que na língua portuguesa antiga se chamava de particípio presente. É o que fez e continua fazendo; e o amante é o inesperado muito embora sempre desejado. Ele é a diferença do estabelecido, do oficial que, porque sabido, não é mais reconhecido. Ainda o amante não só aparece distintamente, mas redescobre o que se tem e se desconhece. Nunca se vê tanto uma coisa do que quando dela desviamos o olhar. De igual modo, pouco se vê do que se vê constantemente. "A rotina foi o que uma vez lutamos tanto para ter e uma vez obtido o perdemos.” (Epicuro, 1988; p.18)

$\mathrm{O}$ amante parece ser mais ardente e jovial porque ele não possui, não tem o outro. $\mathrm{O}$ desafio que se impõe é ser permanente e comportar-se como não sendo. O amar, o saber, se manifestam uma vez se reconheça que ainda não se ama, não se sabe. É por isso que a carência somente é superada quando for reconhecida como a realidade vigente. De igual modo, não há possibilidade de melhorar o que se faz se não houver a dúvida sobre o que se faz. Essa dúvida (duo-habes = há dois ou duas) é que permite que a diferença se manifeste. Hegel, em "Fenomenologia do Espírito", diz que o sabido, por ser tido como o sabido, não é, na verdade, sabido. Se a realidade é sempre outra o tempo todo, então o empenho de conhecê-la não pode ser menos constante. A verdade da realidade é um resgate permanente e incessante. Por isso, também, estar com o outro não é pouca coisa, nem pouco exigente. "A mudança do outro me desorienta. 
Sua mudança compromete nosso relacionamento atual. Eu não posso mais fazer com ele como sempre fiz. Sua mudança me obriga a mudar. Um pouco antes, as coisas estavam todas 'nos seus lugares', e eu podia caminhar sonambulicamente de uma parte para a outra, sem prestar atenção. Agora que ele mudou, tudo fica incerto". (Gaiarsa, 1976)

Como se afirmou até o momento, o outro precisa ser levado em consideração, mas isso não deve ser tomado como se esse outro fosse o eixo da relação. Isso não contempla uma abordagem de completude, pois tão-somente desloca a atenção do eu para o outro. Cabe mencionar aqui que o outro não é o lugar da perfeição, mas como cita Sartre em "A Náusea" (1938), o inferno é o outro! Nesse sentido, a completude entre o eu e o outro não é de mero acoplamento, posto que não se trata de seres divididos que buscam no outro sua metade. O conflito é a constante entre o eu e o outro. É, novamente, um processo de vida e de morte, de construir e destruir, de oferecer, aceitar e recusar. $\mathrm{O}$ que se sabe do outro não ultrapassa a suspeita, muito embora na suspeita algo do outro já esteja presente, pois a suspeita apóia-se na percepção que se tem do outro. Não se pode ter a exacerbação do conflito resultando na destruição do eu ou do outro, posto que isto implica a destruição do que fica, já que fica sem referência. A ausência do outro é uma presença. "A tradição de todas as gerações mortas oprime como um pesadelo o cérebro dos vivos". (Marx, 1888; p.7), mas ocorre a grande possibilidade do outro tornar-se uma projeção do eu. Aqui retornamos ao ensimesmamento do eu.

A verdade do eu e do outro está na relação entre eles. É o que eles estabelecem entre si que encarna o mais relevante. Por ser uma relação entre diferentes, e é isso que funda a relação, a contradição, o conflito, tornam-se aguilhões regulares.

A sala de aula é a relação entre o professor e o aluno. Um encontra no outro sua identificação e, concomitantemente, sua negação, pois o professor pressupõe o aluno $e$ vice-versa. O professor nega o aluno porque este necessita ir além do que é para tornarse realmente o que é. A semente é a árvore, mas precisa deixar de ser o que é para poder realizar o que mais pode ser. O aluno, por sua vez, nega ao professor o perfil do que ensina para cobrar-lhe a aprendizagem, posto que o desconcerto provocado exige um novo olhar sobre este outro, o aluno. O resultado é uma nova empreitada didática, metodológica, motivacional e estratégias pedagógicas. Por falar em pedagogia, vale mencionar que o pedagogo, etimologicamente, é o que acompanha a criança à escola! Para Freud esse acompanhamento demanda uma profunda compreensão da alma infantil. Além disso, o outro nunca estará em plena consonância com o eu. Se Rousseau estiver certo ao dizer que o homem nasce livre e por toda a parte encontra-se 
escravizado, então a massificação seria absoluta na sociedade, mas, ainda assim, as reações seriam as mais diversas possíveis. O trauma apresenta-se, diferentemente, nos indivíduos certamente pela singularidade da história de cada um.

Assim sendo, resta ao professor o remexer a experiência do aluno, provocando o reconhecimento dele pelo próprio aluno e a realização mais consciente de sua elaboração. Para o pai da Psicanálise, isto equivale a matar o genitor, a cortar o cordão umbilical reconhecendo o passado, condição para superá-lo, mas abrindo-se para uma criação. "Eu não podia admitir que a gente recebesse o ser de fora, que ele se conservasse por inércia, nem que os movimentos da alma fossem os efeitos de movimentos anteriores (...). Diziam-me amiúde: o passado nos impele; mas eu estava convencido de que o futuro me puxava." (Sartre,1970; p.29)

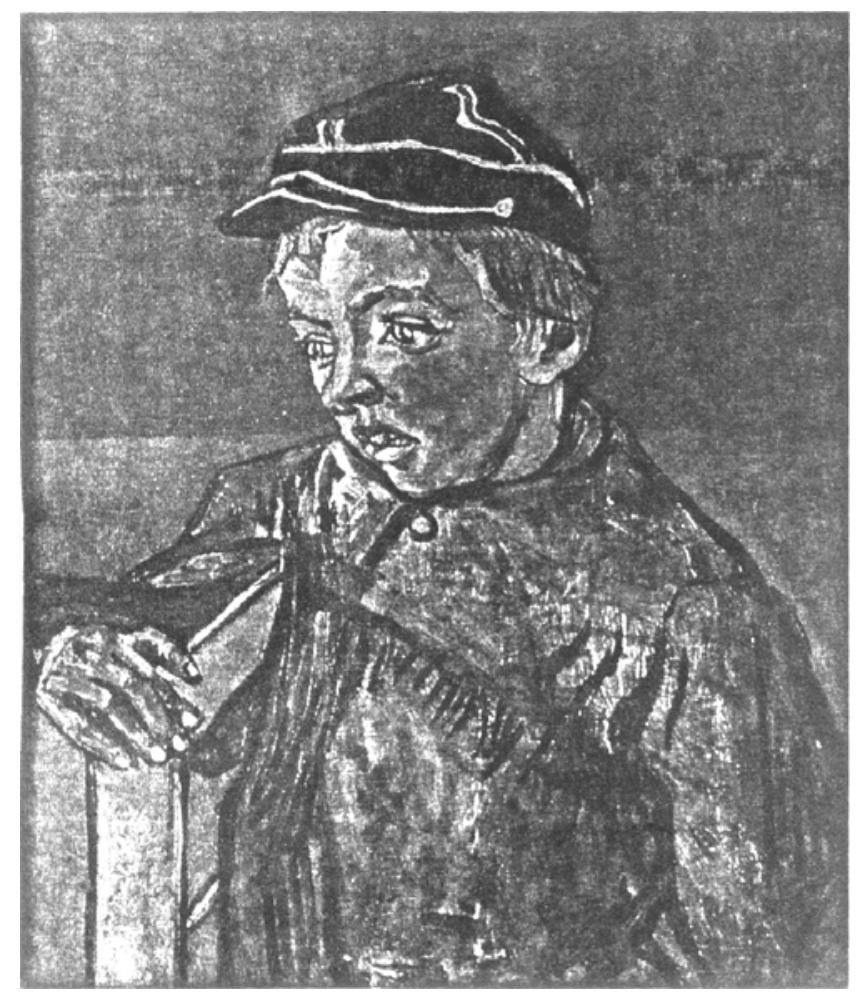

O Escolar (O Filho do carteiro), VINCENT VAN GOGH, Museu de Arte de São Paulo, São Paulo. 
O espaço da sala de aula não somente resulta da relação professor-aluno, mas também age sobre tal relação condicionando-a e domesticando-a. Não poucas vezes professor e aluno ocupam esse espaço automaticamente. Vivem momentos de morte (Tolstói), pois desconhecem o que acontece. Esse desconhecimento tem sua origem no que se acredita conhecer e, como já foi dito anteriormente, deixa de ser investigado. Todo dia... tudo é feito sempre igual! Tomás de Aquino coloca que a percepção do que se sabe é a percepção, na mesma medida, da própria ignorância. Em outras palavras, o contato intenso com a investigação científica ou especulação intelectual aponta para a necessidade de se reconhecer os limites do que se sabe e, portanto, do desconhecido. Para o professor isso significa a "possibilidade" de uma consciência maior do que ocorre. Por conseguinte, o espaço da sala de aula pode e deve ser desestruturado permanentemente. A certeza sensível, primeira etapa do processo de conhecimento segundo Hegel em sua "Fenomenologia do Espírito", e, precisamente por isso, a mais abstrata e vazia, calcifica os fazeres e funções entre professor e aluno. Assim, a decepção ou desmantelamento sobre quem e o que ser impõe-se como imperativo. O aluno não é menos construtor que o professor, mas não atinge o que pode ser sem uma mediação. $O$ professor, obviamente, não é a única mediação possível, às vezes nem a melhor, mas é um momento da relação e muito privilegiado porque está aí para o outro. Nietzsche sugere que aquele que pretende estabelecer uma relação com alguém tem que se perguntar se é capaz de conversar com esse alguém por algum tempo. Conversar exige atenção à fala do outro. Caso contrário, o diálogo torna-se monólogo.

A sala de aula enquanto espaço de encontro, daí ocupado, é local de exigências e desafios, posto que é isso que resulta do estar com o outro. Nunca se está o suficiente com o outro, pois o encontro é negado em seu próprio acontecer. Isso significa que o ato de estar junto deve ser investigado segundo o que pode ser para que possa ser mais do que é. Por isso, professor e aluno necessitam estar constantemente atentos ao que são para não calcificar o próprio ser e inibir outras possibilidades.

Trata-se de um encontro entre humanos e, talvez, precisamente devido a isso, tenham-se desencontros. Marx confessaria à sua filha Jenny que sua máxima preferida era a de que nada que é humano me é estranho indicando que se, por um lado, o humano não seja de fácil definição, por outro, envolvia uma atitude de permanente busca desse humano. Ser professor e ser aluno, estar na sala de aula, pede a apreciação pelo que aí acontece como condição que conduz ao saber sobre esse espaço. 


\section{REFERÊNCIAS BIBLIOGRÁFICAS}

EPICURO. Antologia de textos. São Paulo: Nova Cultural, 1988.

FOUCAULT, M. Vigiar e Punir. Petrópolis: Vozes, 1980.

FREUD, S. Obras psicológicas: antologia. Rio de Janeiro: Imago, 1992.

GAIARSA, J. A. A estátua e a bailarina. São Paulo: Brasiliense, 1976.

A engrenagem e a flor. São Paulo: Taika, 1974.

HEGEL, G. W. F. Ciencia de la Lógica. Buenos Aires: Hachette, 1968.

Fenomenologia do Espírito. Petrópolis: Vozes, 1992.

MARX, K. O 18 Brumário de Luis Bonaparte. São Paulo: Nova Cultural, 1987-1988.

MARX, K., ENGELS, F. Textos. São Paulo: Ed. Sociais, 1975, 1976 e 1977. 3V.

GORMAN, P. Pitágoras: uma vida. São Paulo: Círculo do Livro, 1979.

SARTRE, J. P. As Palavras. Rio de Janeiro: Nova Fronteira, 1982.

La Nausée. Paris: Gallinard, 1932. 